of the contents. And, paying due deference to the slight sensitivity of the editors to criticism (see preface), a fervent hope is that this trend will be maintained in subsequent editions. To pluck just two examples out of the mud, dinitrogen fixation and one-carbon metabolism are topics which merit the detailed attention of the editors in future. Both provide instances of important metabolic principles - and both are subjects of importance in the comprehension of the biochemistry of bacterial growth.

The book is a compilation of chapters written by different authors, but for once it is not a discordant collection of writings; the editors have exercised considerable skill in maintaining the interest of the reader.

The book starts with a chapter on the anatomy of the bacterium and proceeds via the mechanism of synthesis and provision of building blocks and relevant genetics to the very important, but frequently neglected, subject of differentiation. The most recently recruited editor, Ian Dawes, makes a creditable first stab at this last topic, enough to encourage aficionados in their expectations that the treatment will be further expanded in the next edition. A very useful appendix, or miscellany, winds up the treatise - particularly useful is the taxonomic summary.

A final comment is reserved for the organization of the book, a mild foray into pedagogy whch might prove successful. A bird's eye view of the contents (an abstract) leads to an abbreviated version (highlighting the principles) so permitting the following very full treatment which does not have to be continually interpreted (spoiled) by signals to the student. This is an excellent text to be recommended to all microbiologists, not just students.

The last book, Introduction to Bacteria, is a first venture of distinct promise designed for students of biology who require slightly more than a nodding acquaintance with microbiology. It will also serve as a useful survey of the subject for students contemplating specialization in microbiology. A few minor irritations jar a little - for example, milk sugar can be safely revealed to be lactose in the next edition; the very artificial separation of cyanobacteria from all other bacteria is not merited (i.e. some species can photosynthesize anaerobically using hydrogen sulphide as an electron donor); and neither meiosis nor mitosis are mechanisms of cell separation.

These sorts of peccadillos aside, this is a well-conceived text written by authors who clearly have a very good insight into recent literature (i.e. their prejudices coincide with those of the reviewer). One could quibble with the brevity of treatment in some instances but, all in all, Introduction to Bacteria is a welcome addition to the fold.

R. Whittenbury is Professor of Biological Sciences at The University of Warwick.

\section{Quart in a pint pot}

D.D. Davies

Plant Cell Structure and Metabolism, 2nd Edn.

By J.L. Hall, T.J. Flowers and

R.M. Roberts. Pp.539.

Longman: 1982. f12.95, \$22.

THE recently completed series $A$ Comprehensive Treatise on Plant Biochemistry, edited by P.K. Stumpf and E.E. Conn, has the laudable object of reviewing all the aspects of plant biochemistry. That series, however, consists of eight volumes at a cost which restricts its purchase to libraries. This second edition of Plant Cell Structure and Metabolism makes a valiant attempt to keep up with recent advances and additionally to relate biochemistry to the structural organization of cells, illustrated by 90 electron micrographs. The authors' admirable effort is achieved with a 27 per cent increase in size over the first edition, but the book still comes at a price which students can afford.

The distillation of wine to produce brandy can be achieved with little loss of alcohol, but the concentration of biochemistry and cell physiology into a

single volume requires the elimination of many important topics. Individual readers will check to see if their selection accords with that made by the authors.

My prejudice is that the failure to discuss plant hormones is a mistake. I found the discussion of metabolic control inadequate and that of the control of glycolysis erroneous, as well as being out-dated. I would in particular take issue with the authors' claim that "Chapter 2 gives a sufficient background of cell chemistry for the book to be read without the aid of other biochemical texts"'. Students should be encouraged to increase their understanding of chemistry and not lulled into a false sense of security by a mere 87 pages on the subject. Moreover, the teaching of chemistry in schools has changed, so that students will know the structure of ethanoic acid but not that of acetic acid! A new book should recognize changes in nomenclature.

These adverse comments must be seen against the overall excellence of the book. It is a worthy modern biochemical equivalent to Haberlandt's classic Physiological Plant Anatomy and should be owned by every serious student of botany.

D.D. Davies is a Professor in the School of Biological Sciences, University of East Anglia.

\section{Pathology for the botanist}

\section{R.K.S. Wood}

Virology of Flowering Plants.

By W.A. Stevens.

Blackie/Chapman \& Hall: 1983. Pp.182. Hbk £17.50, \$39.95; pbk £8.50, \$18.95.

Plant Pathology and Plant Pathogens, 2nd Edn.

By C.H. Dickinson and J.A. Lucas. Blackwell Scientific/Halsted: 1982.

Pp.230. f7.80, \$17.95.

Principles of Plant Pathology.

By J.G. Manners.

Cambridge University Press: 1982.

Pp.264. Hbk £22.50, \$47.50; pbk £8.95, $\$ 17.95$.

PLANT pathology has long had a prominent role in the teaching of agricultural sciences. But only relatively recently has it also become important in the teaching of plant sciences - including much of microbiology - and it will become more so with the expansion of technologies based on plant sciences. Because of past neglect, however, there are still not all that many books on plant pathology and fewer still on plant viruses at levels taught to undergraduates in Britain and presumably elsewhere. The three books reviewed here are intended to serve these levels.

Stevens's Virology of Flowering Plants has a good introductory chapter, apart perhaps from the undue emphasis on cryptograms which is out of place. The second chapter on symptoms has a good text and diagrams but the photographs of symptoms are mostly poor, a pity because symptoms of virus diseases are often so eye-catching. Chapter 3 on transmission of viruses to plants is efficiently comprehensive for a book of this size - the diagrams again being much more useful than the photographs - and the following two chapters, on structure and on replication, are well illustrated with a clear text despite the complexities which may be somewhat beyond the needs of most undergraduates.

The control of the diseases is well summarized in the penultimate chapter, and the book ends somewhat surprisingly but refreshingly with an account of techniques - but would this chapter not be better placed after the Introduction? The bibliography of some 300 references is long and divided according to chapters. Only students can tell how useful this is, but they are likely to be well satisfied with the rest of the book as a clear and comprehensive introduction to the subject.

The other two books, both dealing with plant pathology, are very different in style and content from Virology of Flowering Plants in being more about principles and based less on detail. Viruses are included by both Dickinson and Lucas, and Manners, but there is not much about them compared with microorganisms. 